\title{
Comparison between leached metakaolin and leached diatomaceous earth as raw materials for the synthesis of ZSM-5
}

\author{
Wilson Aguilar-Mamani ${ }^{1,2^{*}}$, Gustavo García ${ }^{1,3}$, Jonas Hedlund ${ }^{1}$ and Johanne Mouzon ${ }^{1}$
}

\begin{abstract}
Inexpensive raw materials have been used to prepare $\mathrm{ZSM}-5$ zeolites with $\mathrm{SiO}_{2} / \mathrm{Al}_{2} \mathrm{O}_{3}$ molar ratios in the range 20 - 40. Kaolin or Bolivian diatomaceous earth was used as aluminosilicate raw materials and sodium hydroxide and $n$-butylamine were used as mineralizing agents and template. Dealumination of the raw materials by acid leaching made it possible to reach appropriate $\mathrm{SiO}_{2} / \mathrm{Al}_{2} \mathrm{O}_{3}$ ratios and to reduce the amount of iron and other impurities. After mixing the components and aging, hydrothermal treatment was carried out and the products were recovered The results clearly show for the first time that well-crystallized ZSM-5 can be directly prepared from leached metakaolin or leached diatomaceous earth using sodium hydroxide and $n$-butylamine as mineralizing agents and template under appropriate synthesis conditions. A longer induction time prior to crystallization was observed for reaction mixtures prepared from leached diatomaceous earth, probably due to slower digestion of the fossilized diatom skeletons as compared with that for microporous leached metakaolin. The use of leached diatomaceous earth allowed higher yield of ZSM-5 crystals within comparable synthesis times. However, low amounts of Mordenite formed, which was related to the high calcium content of diatomaceous earth. Another considerable advantage of diatomaceous earth over kaolin is that diatomaceous earth does not require heat treatment at high temperature for metakaolinization.
\end{abstract}

Keywords: Kaolin; Diatomaceous earth; n-butylamine; ZSM-5 zeolite

\section{Introduction}

The zeolite ZSM-5 (Zeolites Socony Mobil) is an aluminosilicate with high silica ratio with suitable properties for catalysis, adsorption and membrane applications (Jacobs 1981, Tavolaro and Drioli 1999, Weitkamp 2000). Researchers (Argauer and Landolt 1972) of Mobil Oil Corporation obtained the first patent on the synthesis of ZSM-5 zeolite, in which they described that this zeolite can be formed with molar ratios of $\mathrm{SiO}_{2} / \mathrm{Al}_{2} \mathrm{O}_{3}$ varying between 20 and 120. Depending on this ratio, the acidity and surface properties of ZSM-5 vary and therefore it is important to carefully control this parameter in the final product (Armaroli et al. 2006, Shirazi et al. 2008).

Typical syntheses of ZSM-5 require sources of silicon and aluminium, a mineralizer (e.g. $\mathrm{OH}^{-}$or $\mathrm{F}^{-}$) and an

\footnotetext{
* Correspondence: gonzalo316@gmail.com

${ }^{1}$ Chemical Technology, Luleå University of Technology, Luleå, Sweden ${ }^{2}$ Department of Chemistry, Faculty of Science and Technology, San Simon University, Cochabamba, Bolivia

Full list of author information is available at the end of the article
}

organic molecule as templating agent. Quaternary ammonium compounds like tetrapropyl ammonium bromide (TPA-Br) (Padovan et al. 1984, Shirazi et al. 2008) and tetrapropyl ammonium hydroxide (TPA-OH) (Kotasthane and Shiralkar 1986) are mostly used for the synthesis of ZSM-5. Unfortunately, these quaternary ammonium compounds are rather expensive. The molecule $n$-butylamine was reported (Sang et al. 2004, Zhao 2005, Martins et al. 2006, Feng et al. 2009) as an alternative templating agent to replace TPA-Br and TPA-OH and is about 100 times less expensive on a molar basis. In the past two decades, efforts have also been undertaken to identify inexpensive $\mathrm{Si}$ and $\mathrm{Al}$ sources to synthesize ZSM-5(Chareonpanich et al. 2004, Sanhueza et al. 2004, Mignoni et al. 2007, Aliev et al. 2011) and it has been shown that kaolin clay and diatomaceous earth are two suitable and inexpensive sources of silica and alumina.

Kaolin clay contains kaolinite with a $\mathrm{SiO}_{2} / \mathrm{Al}_{2} \mathrm{O}_{3}$ molar ratio close to 2 and therefore it is well suited for the preparation of low-silica zeolites such as zeolite A (Costa 
et al. 1988, Murat et al. 1992, Chandrasekhar et al. 1997, Sanhueza et al. 1999). To obtain this zeolite from kaolin, two steps are necessary: first, a thermal treatment of kaolin to obtain an amorphous and reactive material denoted metakaolin. The second step is a hydrothermal treatment to convert metakaolin to zeolite in an alkaline aqueous medium. Preparation of zeolites with higher $\mathrm{SiO}_{2} / \mathrm{Al}_{2} \mathrm{O}_{3}$ molar ratios such as zeolites $\mathrm{X}$ (De Lucas et al. 1992, Caballero et al. 2007, Colina and Llorens 2007) and Y (Bosch et al. 1983, Atta et al. 2007) from kaolinite has also been reported. However, the syntheses of these zeolites require either an increase of the amount of silica or partial removal of aluminium. The first alternative implies using an additional source of silica with high solubility, e.g. sodium silicate. The second alternative, i.e. dealumination, consists in either leaching kaolin in a solution of an inorganic acid $\left(\mathrm{HCl}, \mathrm{H}_{2} \mathrm{SO}_{4}, \mathrm{HNO}_{3}\right)$ (Ford 1992) or alternatively calcining the kaolin with an inorganic acid $\left(\mathrm{H}_{2} \mathrm{SO}_{4}\right)$ (Colina et al. 2001, Colina et al. 2002)

The synthesis of ZSM-5 zeolite from kaolin with additional sources of silica has been reported in patent (Reid 1982) and research papers (Khatamian and Irani 2009, Kovo et al. 2009). Dealumination of metakaolinite to synthesize ZSM-5 has also been investigated (Madhusoodana et al. 2005); (Zhang et al. 2007); (Madhusoodana et al. 2001). In all these studies, expensive tetrapropylamine was used as template. The synthesis of ZSM-5 with a high $\mathrm{SiO}_{2} / \mathrm{Al}_{2} \mathrm{O}_{3}$ molar ratio from metakaolin and silica sol and less expensive $n$-butylamine has been reported (Feng et al. 2009). However, to the best of our knowledge, a combination of dealumination of metakaolin by acid treatment together with the use of $n$-butylamine as a template has not yet been reported.

Diatomaceous earth is another inexpensive source of silica, which is a sedimentary rock comprised of fossilized skeletal remains of diatoms. It consists essentially of amorphous hydrated silica and a small amount of alumina and also impurities such as iron (Sanhueza et al. 2003). It can be used to produce mesoporous material such as MCM-41 (Sanhueza et al. 2006) and also both low and high silica zeolites such as A (Ghosh et al. 1994), P (Wajima et al. 2008) or $\mathrm{NaP}$ (Wajima et al. 2006), analcime (Chaisena and Rangsriwatananon 2005); (Rangsriwatananon et al. 2008), cancrinite (Chaisena and Rangsriwatananon 2005), hydroxisodalite (Chaisena and Rangsriwatananon 2005), NaY (Chi et al. 2011) and mordenite (Sanhueza et al. 2003). In most of these syntheses, the raw diatomaceous earth was acid treated to remove iron and other impurities. The conversion of diatomaceous earth to ZSM-5 was also studied in combination with other raw materials such as paper sludge ash (Wajima et al. 2008) or volcanic ash (Aliev et al. 2011). However, there are a few studies on the synthesis of ZSM-5 by using only diatomaceous earth as silica source. In these studies, diethanolamine(Sanhueza et al. 2004) and expensive tetrapropylammonium bromide (Shan et al. 2004) were used as templates and these synthesis required quite long crystallization times from 40 hours to 6 days at a quite high temperature of $180^{\circ} \mathrm{C}$.

In the present work, we show for the first time that leached metakaolinite or diatomaceous earth in combination with sodium hydroxide and $n$-butylamine can be used as inexpensive raw materials for the synthesis of ZSM-5 without using an additional source of silica. However, both sources of alumino-silica are shown to behave differently during the course of synthesis and to lead to slightly different reaction products. In particular, we discuss these discrepancies in terms of composition, morphology, and porosity of the raw materials.

\section{Experimental}

\section{Raw materials}

Kaolin (Riedel de Haen, pro analysi), diatomaceous earth (Murmuntani zone in the locality of Llica, Potosi, Bolivia), sodium hydroxide (Sigma Aldrich, reagent grade, $\geq 98 \%$, anhydrous pellets), $n$-butylamine (Sigma Aldrich, 99.5\%) and hydrochloric acid (Merk, pro analysi 37\%) were used as reagents.

\section{Heat treatment}

Kaolin was first calcined in a porcelain crucible that was placed in a furnace and heated at a rate of $8^{\circ} \mathrm{C} / \mathrm{min}$ in air. When the temperature reached $750^{\circ} \mathrm{C}$, this temperature was maintained for $2 \mathrm{~h}$ to obtain metakaolin and the temperature in the furnace was then reduced to room temperature. It was not necessary to carry out the heat treatment for the diatomaceous earth in order to obtain ZSM-5, and consequently, this material was not heat treated. On the other hand, if the heat treatment of kaolin was omitted, no zeolite formed.

\section{Dealumination of raw materials}

Metakaolin and diatomaceous earth were acid leached in a spherical glass container under reflux conditions in a thermostated oil bath maintained at $115^{\circ} \mathrm{C}$. Metakaolin or diatomaceous earth was stirred in hydrochloric acid (3 M) for 150 minutes. The metakaolin or diatomaceous earth to acid weight ratio was $1: 17$. Subsequently, the suspension was quenched and the acid leached product was washed with distilled water. Finally, the product was separated by filtration and the filter cake was washed with distilled water until the $\mathrm{pH}$ reached a value close to 7 .

\section{Hydrothermal synthesis}

The synthesis mixtures were prepared by mixing the aluminosilicate sources with distilled water, $n$-butylamine 
(NBA) and sodium hydroxide. The molar ratios in the synthesis mixtures were: $\mathrm{Na}_{2} \mathrm{O} / \mathrm{SiO}_{2}=0.18 ; \mathrm{SiO}_{2} / \mathrm{Al}_{2} \mathrm{O}_{3}=$ $\mathrm{X} ; \mathrm{SiO}_{2} / \mathrm{NBA}=7 ; \mathrm{H}_{2} \mathrm{O} / \mathrm{SiO}_{2}=30$, where $\mathrm{X}=33$ and 44 for leached metakaolin and leached diatomaceous earth, respectively. The mixtures were aged under stirring for 24 hours at room temperature and were thereafter hydrothermally heated in Teflon lined stainless steel autoclaves kept for different times in an oil bath at $165^{\circ} \mathrm{C}$. After hydrothermal treatment, the solids were recovered by filtration and washed with distilled water until the $\mathrm{pH}$ reached a value close to 7 . The powders were dried at $100^{\circ} \mathrm{C}$ overnight and finally calcined at $550^{\circ} \mathrm{C}$ for 6 hours to remove the template.

\section{Characterization of the products}

The chemical compositions of kaolin, diatomaceous earth, leached aluminosilicates and the final products were determined using inductively coupled plasma-sector field mass spectrometry (ICP-SFMS). Samples of $0.1 \mathrm{~g}$ were fused with $0.4 \mathrm{~g}$ of $\mathrm{LiBO}_{2}$ and dissolved in $\mathrm{HNO}_{3}$. Crystallinity was examined by X-ray diffractometry (XRD) using a PANalytical Empyrean X-ray Diffractometer equipped with $\mathrm{Cu}$ LFF HR X-ray tube, a graphite monochromator, and a PIXcel3D detector. The X-ray tube was operated at $30 \mathrm{~mA}$ and $40 \mathrm{kV}$. The investigated $2 \theta$ range was from 5 to $50^{\circ}$ with a step size of $0.026^{\circ}$. The degree of crystallinity was calculated by using the area of characteristic peaks of ZSM- 5 between 22 and $25^{\circ}$ after background removal following the equation by van Hooff (Vanhooff et al. 1991).

ZSM-5 crystals with an average length of $10 \mu \mathrm{m}$ synthesized from silicic acid and TPAOH by following the method reported by Lechert and Kleinwort (Robson and Lillerud 2001) were used as standard.

The morphology of the ZSM-5 crystals was studied by scanning electron microscopy (SEM, Magellan 400, FEI Company) without coating. The chemical composition of individual crystals was determined by energy dispersive spectrometry (EDS, $80 \mathrm{~mm}^{2} \mathrm{X}$-max detector, Oxford Instruments) at an accelerating voltage of $10 \mathrm{kV}$. Nitrogen adsorption-desorption data were recorded with an ASAP 2010 equipment from Micrometrics to determine the BET specific surface area, total pore volume and micropore volume of the raw materials and reaction products, as well as the reference crystals. The weight percentage of solid retentate after aging was determined by filtration through a $1 \mu \mathrm{m}$ filter paper and gravimetric method, while the filtrates were analyzed by ICP-SFMS.

\section{Results}

\section{Characterization of the starting materials}

$\mathrm{X}$-ray diffractograms of the raw aluminosilicates and dealuminated counterparts are shown in Figure 1. Kaolin of course contains mostly kaolinite (evidenced by reflections at $2 \theta=12.33 ; 19.80 ; 20.40 ; 21.40 .24 .81$ and 35.11 ) but also traces of quartz $(2 \theta=20.85 ; 26.66)$ and muscovite $(2 \theta=8.83 ; 35.06)$. Kaolin after calcination and leaching was mostly an amorphous material with weak characteristic peaks of muscovite and quartz. On the other hand, raw diatomaceous earth shows the occurrence of halite $\mathrm{NaCl}$ $(2 \theta=27.41 ; 31.76 ; 45.53)$, muscovite $(2 \theta=8.83 ; 27.83$; $35,06)$, albite $(2 \theta=22.03 ; 23.70)$ and quartz $(2 \theta=20.85$; 26.66) in addition to amorphous material. After acid treatment and the subsequent washing, the amorphous material remained and $\mathrm{NaCl}$ was removed, but the other minor constituents were still present (muscovite, albite and quartz).

The chemical compositions of the raw and leached materials measured by ICP-SFMS are given in Table 1 . Raw kaolin and diatomaceous earth had a $\mathrm{SiO}_{2} / \mathrm{Al}_{2} \mathrm{O}_{3}$ molar ratio of 2.2 and 15 , respectively. This ratio was successfully increased by acid leaching to 33 and 44 for kaolin and diatomaceous earth, respectively. Acid leaching also reduced significantly the concentration of impurities in both materials. Finally, the leached materials had comparable compositions in terms of magnesium, potassium and iron. However, leached diatomaceous earth was approximately 4 times richer in sodium and calcium, which can be understood from the presence of $\mathrm{NaCl}$ and calcium compounds in the raw diatomaceous earth originating from a region close the salt lake Uyuni.

Figure 2 shows the morphology of the raw materials and leached materials revealed by SEM. Kaolin is composed of stacks of platelets with hexagonal symmetry which is typical of natural kaolinites (Figure 2(a)). The leached metakaolin (Figure 2(b)) has very similar platelet morphology but the surface area increased from 12 to $288 \mathrm{~m}^{2} / \mathrm{g}$ as presented in Table 2 . This is not surprising since acid-leached metakolin is known to form microporous silica (Madhusoodana et al. 2001); (Zhang et al. 2007). Raw diatomaceous earth (Figure 2(d)) exhibited large particles with typical shapes of diatomaceous biogenic sediments. Some diatomaceous earth particles were partially broken in smaller pieces by the mechanical action of stirring during the acid treatment but their characteristic shapes could still be distinguished (Figure 2(e)). Leaching of diatomaceous earth only caused a slight increase in specific surface area (from 38 to $55 \mathrm{~m}^{2} / \mathrm{g}$; Table 2).

\section{Hydrothermal synthesis}

Hydrothermal synthesis in terms of composition of the synthesis mixture and synthesis time was first optimized to maximize the yield of ZSM-5 using leached metakaolin as a raw material. The composition used in this work was found to produce the highest yield of ZSM-5 crystals. Figure 3 shows the evolution of XRD crystallinity compared with a reference sample composed of 6-10 $\mu \mathrm{m}$ ZSM-5 crystals. It can be noticed in Figure 3(a) that samples prepared from leached metakaolin reached maximum crystallinity for synthesis times between 9 


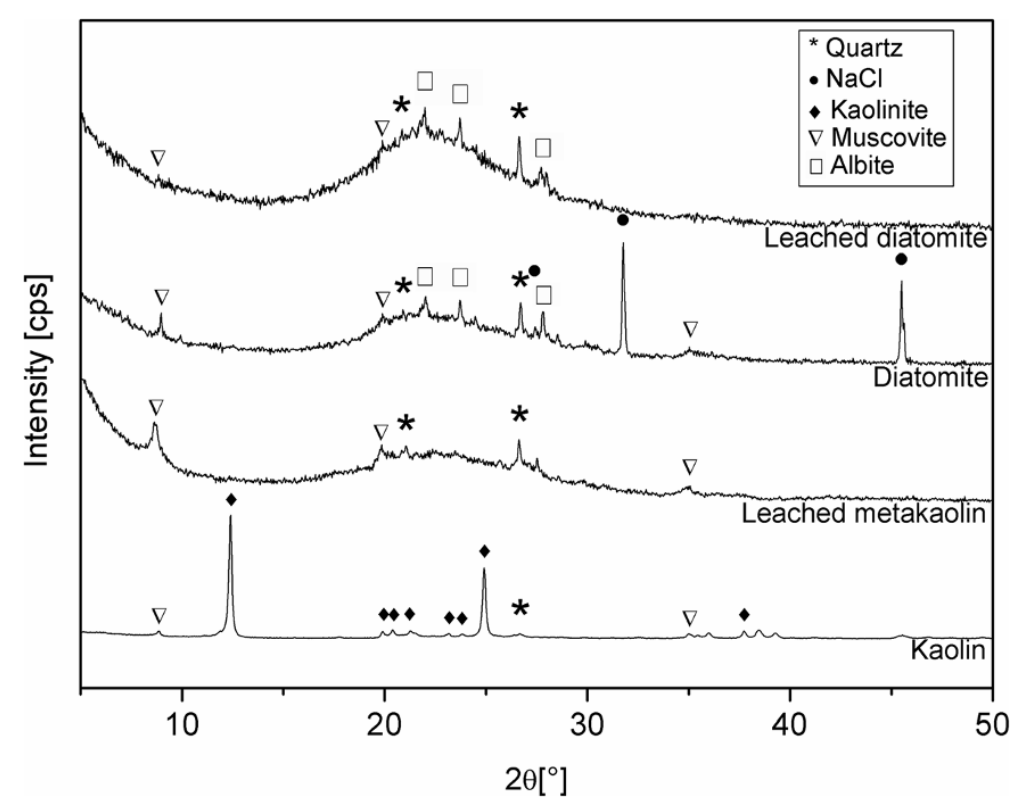

Figure 1 XRD diffractograms of the raw materials and acid-leached materials.

and 12 hours before decreasing for prolonged hydrothermal treatments. The reaction parameters of the dealumination and hydrothermal treatments obtained on kaolin were employed for diatomaceous earth. As shown in Figure 3(b), the best crystallinity for leached diatomaceous earth was obtained for 12 hours of synthesis.

\section{Characterization of the crystalline products}

The diffractograms of the final reaction products obtained from both types of raw materials after $12 \mathrm{~h}$ synthesis are presented in Figure 4. The main characteristic peaks correspond to the MFI structure $(2 \theta=7.9 ; 8.7 ; 23.0$ etc. $)$ in good agreement with the reference pattern PDF-042-0024. The intensities of the main peak of quartz are similar in both samples and of the same order of magnitude as in the leached materials. Therefore, the quartz content is similar in both samples and originates from the raw materials. However, the reaction product obtained from diatomaceous earth contained traces of mordenite, approximately $5 \%$ of the intensity of the main peak of ZSM-5. The composition of the final products after $12 \mathrm{~h}$ synthesis was determined by ICP-SFMS analysis and the results were presented in Table 1 . The average $\mathrm{SiO}_{2} / \mathrm{Al}_{2} \mathrm{O}_{3}$ molar ratio was 23 and 40 for the reaction products obtained from leached metakaolin and diatomaceous earth, respectively. From these data, the reaction products could be considered as quite pure ZSM- 5 with traces of mordenite formed during synthesis and of quartz remaining from the raw material.

The morphology of the reaction products was studied by SEM and typical images were presented in Figure 5. Synthesis from leached metakaolin resulted in the formation of flat tablet shaped ZSM-5 crystals with a diameter of 5-6 $\mu \mathrm{m}$, but also some smaller particles, as shown in Figure 5(a). In contrast, the ZSM-5 crystals obtained from leached diatomaceous earth were rounded with average

Table 1 Compositions (in mole\%) of kaolin, diatomaceous earth, leached metakaolin, leached diatomaceous earth and ZSM-5 products by ICP-SFMS

\begin{tabular}{|c|c|c|c|c|c|c|}
\hline Composition & Kaolin & Leached metakaolin & ZSM-5 (K) & Diatomaceous earth & Leached diatomaceous earth & ZSM-5 (D) \\
\hline $\mathrm{SiO}_{2}$ & 67.7 & 95.9 & 94.0 & 78.8 & 96.4 & 96.0 \\
\hline $\mathrm{Al}_{2} \mathrm{O}_{3}$ & 30.1 & 2.92 & 4.15 & 5.22 & 2.17 & 2.40 \\
\hline $\mathrm{CaO}$ & 0.15 & 0.12 & 0.10 & 4.44 & 0.49 & 0.63 \\
\hline $\mathrm{Fe}_{2} \mathrm{O}_{3}$ & 0.37 & 0.16 & 0.18 & 0.22 & 0.06 & 0.07 \\
\hline $\mathrm{K}_{2} \mathrm{O}$ & 1.13 & 0.60 & 0.65 & 1.29 & 0.33 & 0.30 \\
\hline $\mathrm{MgO}$ & 0.59 & 0.19 & 0.22 & 3.30 & 0.19 & 0.23 \\
\hline $\mathrm{Na}_{2} \mathrm{O}$ & 0.16 & 0.08 & 0.65 & 6.78 & 0.35 & 0.37 \\
\hline $\mathrm{Mol} \mathrm{SiO}{ }_{2} / \mathrm{Al}_{2} \mathrm{O}_{3}$ & 2.2 & 33 & 23 & 15 & 44 & 40 \\
\hline
\end{tabular}



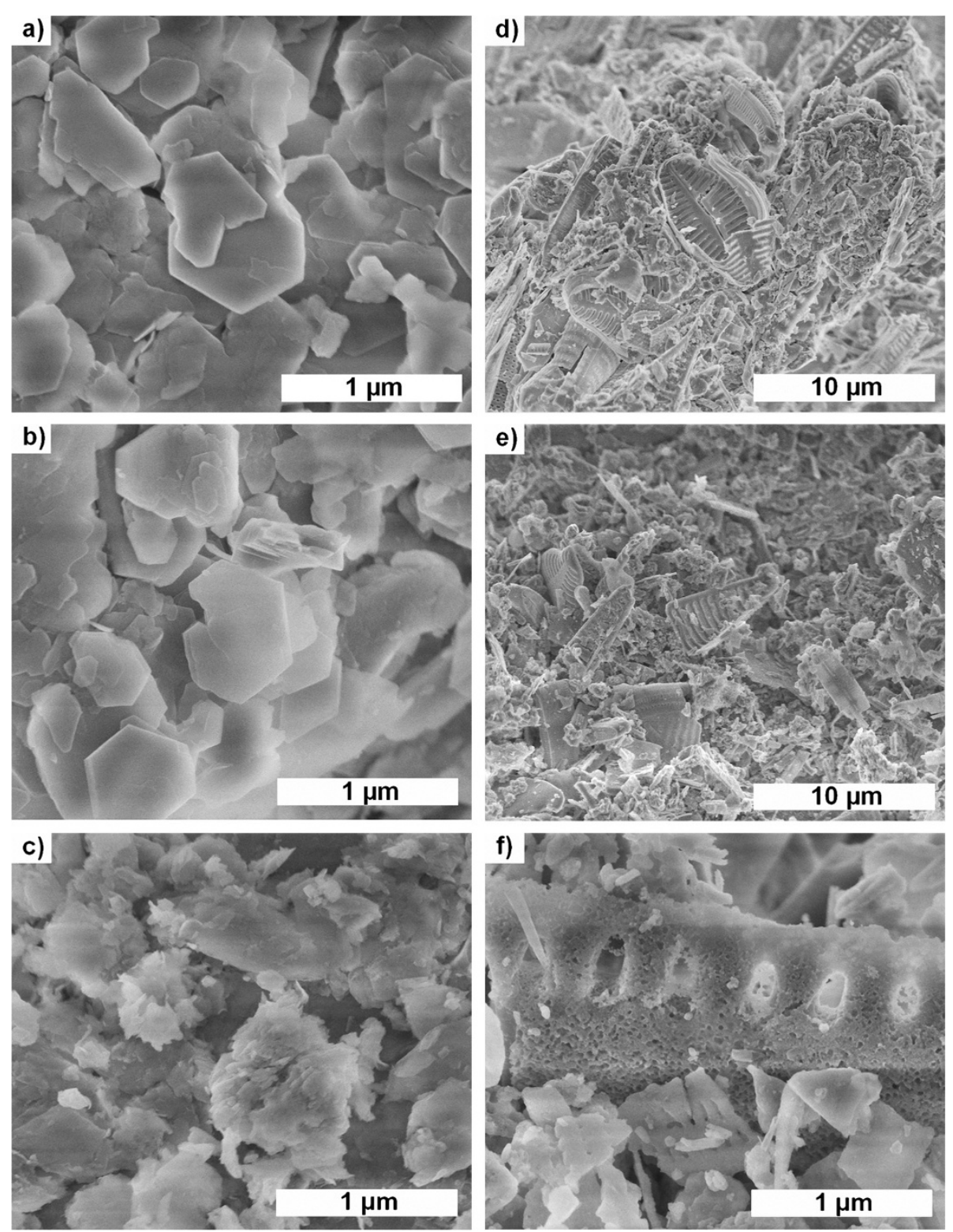

Figure 2 Morphology of the raw materials and leached materials. (a) Kaolin (50000x magnification). (b) Leached metakaolin (LMK) (50000x magnification). (c) Solid part of LMK after aging (50000x magnification). (d) Diatomaceous earth (5000x magnification). (e) Leached diatomaceous earth (LD) (50000x magnification). (f) Solid part of LD after aging (50000x magnification).

Table 2 Surface area and pore volumes derived from nitrogen adsorption data for the raw, leached materials, final products and standard sample

\begin{tabular}{|c|c|c|c|}
\hline Sample & BET surface area $\left(\mathrm{m}^{2} / \mathrm{g}\right)$ & Total pore volume $\left(\mathrm{cm}^{3} / \mathrm{g}\right)$ & Micropore volume $\left(\mathrm{cm}^{3} / \mathrm{g}\right)$ \\
\hline Kaolin & 12 & 0.058 & 0.004 \\
\hline Leached metakaolin & 288 & 0.24 & 0.089 \\
\hline Diatomaceous earth & 38 & 0.093 & 0.003 \\
\hline Leached diatomaceous earth & 55 & 0.11 & 0.006 \\
\hline ZSM-5 (K) & $255(82 \%)$ & 0.17 & $0.082(68 \%)$ \\
\hline ZSM-5 (D) & 298 (96\%) & 0.15 & $0.098(82 \%)$ \\
\hline ZSM-5 standard & 310 & 0.15 & 0.12 \\
\hline
\end{tabular}




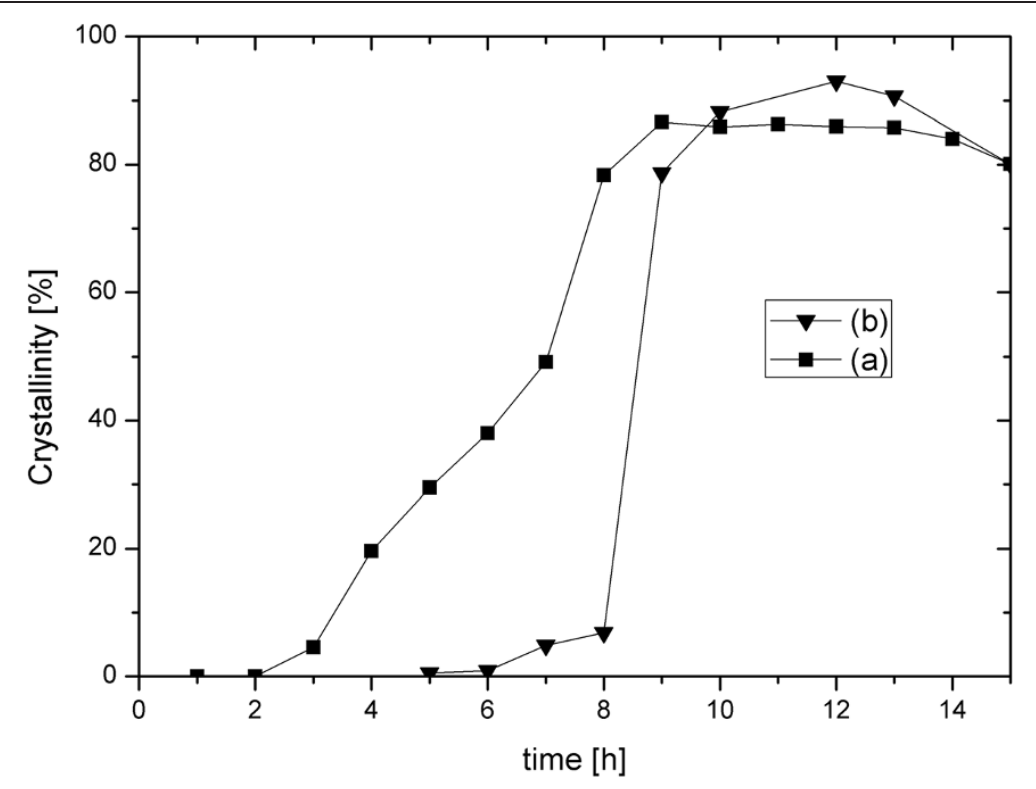

Figure 3 Crystallinity as a function of time of the reaction products prepared from acid leached materials. (a) Leached metakaolin. (b) Leached diatomaceous earth.

diameter around $7-8 \mu \mathrm{m}$ and aspect ratio close to 1 (Figure 5(b)). This sample also contained smaller particles and particularly small slabs as those encircled in Figure 5(b), which were attributed to mordenite.

\section{Discussion}

As shown above, the combination of both sodium hydroxide and $n$-butylamine together with leached metakaolin or leached diatomaceous earth was efficient to produce micron-sized ZSM-5 crystals within similar synthesis times. However, the reaction mechanism seems to differ depending on which alumino-silica source was used. Figure 3(a) clearly shows that crystal growth is triggered after an induction period of $2 \mathrm{~h}$ and slowly progresses until maximum crystallinity is reached after $9 \mathrm{~h}$ when leached metakaolin was used. In contrast, the induction

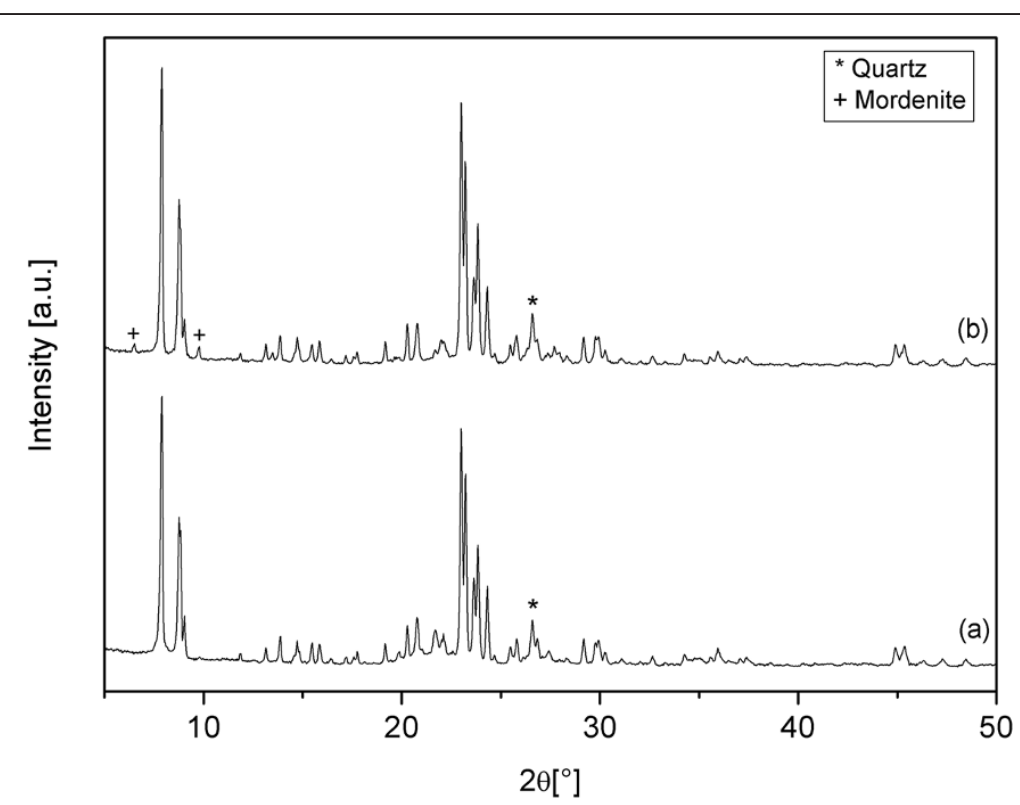

Figure 4 XRD diffractograms of the products obtained after 12 hours of synthesis from acid leached materials. (a) Leached metakaolin. (b) Leached diatomaceous earth. 

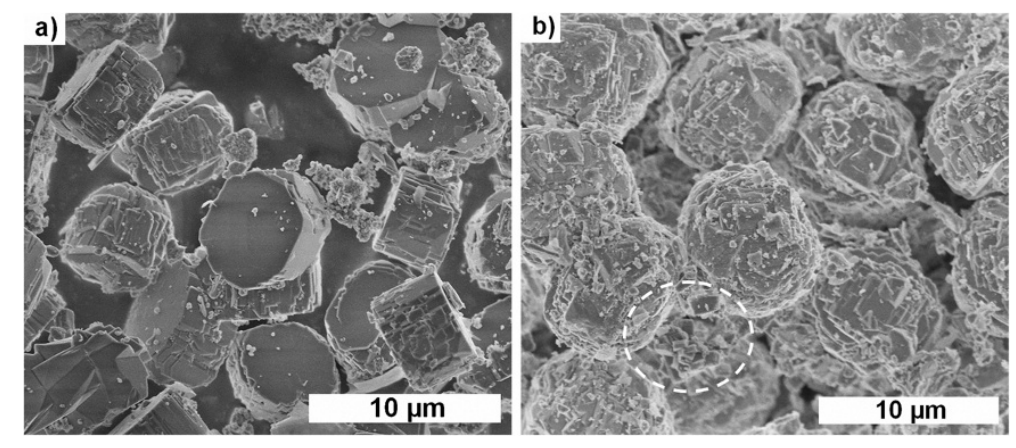

Figure 5 SEM images of ZSM-5 crystals from kaolin and diatomaceous earth. (a) Kaolin (5000x magnification). (b) Diatomaceous earth (5000x magnification).

period was extended to $6 \mathrm{~h}$ before a sudden burst of crystal growth occurred between 8 and 9 h, if leached diatomaceous earth was used as alumino-silica source (Figure 3(b)). The differences in growth rates are not yet understood. However, the difference in induction period between both synthesis mixtures may be related to the state of the synthesis mixtures after $24 \mathrm{~h}$ aging and before hydrothermal treatment. After filtration through a 1- $\mu \mathrm{m}$ filter paper, 26 and $80 \mathrm{wt} . \%$ of the original solid material remained from the aged synthesis mixtures prepared from leached metakaolin and leached diatomaceous earth, respectively. The filtrates were found to be silica-rich sols by ICP-SFMS $\left(\mathrm{SiO}_{2} / \mathrm{Al}_{2} \mathrm{O}_{3}\right.$ molar ratio 400-800). As shown in Figure 2(c), the solid retentate of the aged synthesis mixture prepared from leached metakaolin consisted of poorly defined platelets with a $\mathrm{SiO}_{2} /$ $\mathrm{Al}_{2} \mathrm{O}_{3}$ molar ratio of 7.5 , which probably stem from undigested muscovite or other materials that did not become microporous or possibly sintered upon calcination. On the other hand in Figure 2(f), particles with typical morphology of fossilized diatom still comprised the main constituent of the diatomaceous earth synthesis mixture after aging, even though further communition occurred by mechanical mixing during aging. Therefore, the longer induction time encountered for the leached diatomaceous earth system can be imparted to the heavily condensed state still present after aging in comparison to the silicarich sol resulting from aging of the leached metakaolin mixture, the latter being more homogeneous and requiring less transformation for nucleation of zeolite crystals.

Although induction time was longer, the maximum crystallinity was slightly higher for samples prepared from diatomaceous earth than from kaolin and amounts to 93 and 87\%, respectively, as shown in Figure 3. By a normalization of the BET specific surface area and total micropore volume with respect to the ZSM-5 standard sample also used for determining crystallinity by XRD, we show that the crystallinity of the reaction product obtained from kaolin is in good agreement with the values given in Table 2 with a specific surface area of $82 \%$. The total micropore volume $(68 \%)$ value indicates that the final product prepared from kaolin contains approximately $30 \%$ of non-microporous material in addition to the ZSM-5 crystals. The same values calculated from the BET specific surface area and total micropore volume for the diatomaceous earth-derived product, 96 and $82 \%$ respectively, are higher than that obtained by XRD (93\%). This can be attributed to the presence of mordenite as a by-product in addition to non-microporous materials.

It was not possible to prevent the formation of mordenite by further optimization of the synthesis parameters. Instead, formation of mordenite occurred randomly, probably due to the variability of the diatomaceous earth raw material. Calcium was found to be concentrated in the mordenite crystals as revealed by the comparison of the EDS spectra between uncalcined ZSM-5 (Figure 6(a)) and mordenite (Figure 6(b)) crystals. Therefore, the higher calcium content in leached diatomaceous earth as compared to leached kaolin probably favored the formation of mordenite. The presence of $n$-butylamine as templating agent in the ZSM-5 crystals was also confirmed by EDS, as shown in Figure 6(a) with the characteristic peak of nitrogen and carbon, while that of sodium was quite weak.

The BET specific surface area obtained in this work for the sample prepared from leached diatomaceous earth $\left(298 \mathrm{~m}^{2} / \mathrm{g}\right)$ is comparable with that obtained in the study by Sang et al. ${ }^{9}\left(294 \mathrm{~m}^{2} / \mathrm{g}\right)$, who employed water glass and aluminum sulfate as $\mathrm{Si}$ and $\mathrm{Al}$ sources, respectively. Therefore, Bolivian diatomaceous earth appears as a competitive source of inexpensive raw materials for the synthesis of ZSM-5 crystals. In addition to the higher crystallinity and BET specific surface area achieved in this work compared with kaolin, diatomaceous earth does not require heat treatment at high temperature for metakaolinization.

\section{Conclusions}

The inexpensive raw materials: kaolin, Bolivian diatomaceous earth, sodium hydroxide and $n$-butylamine have 

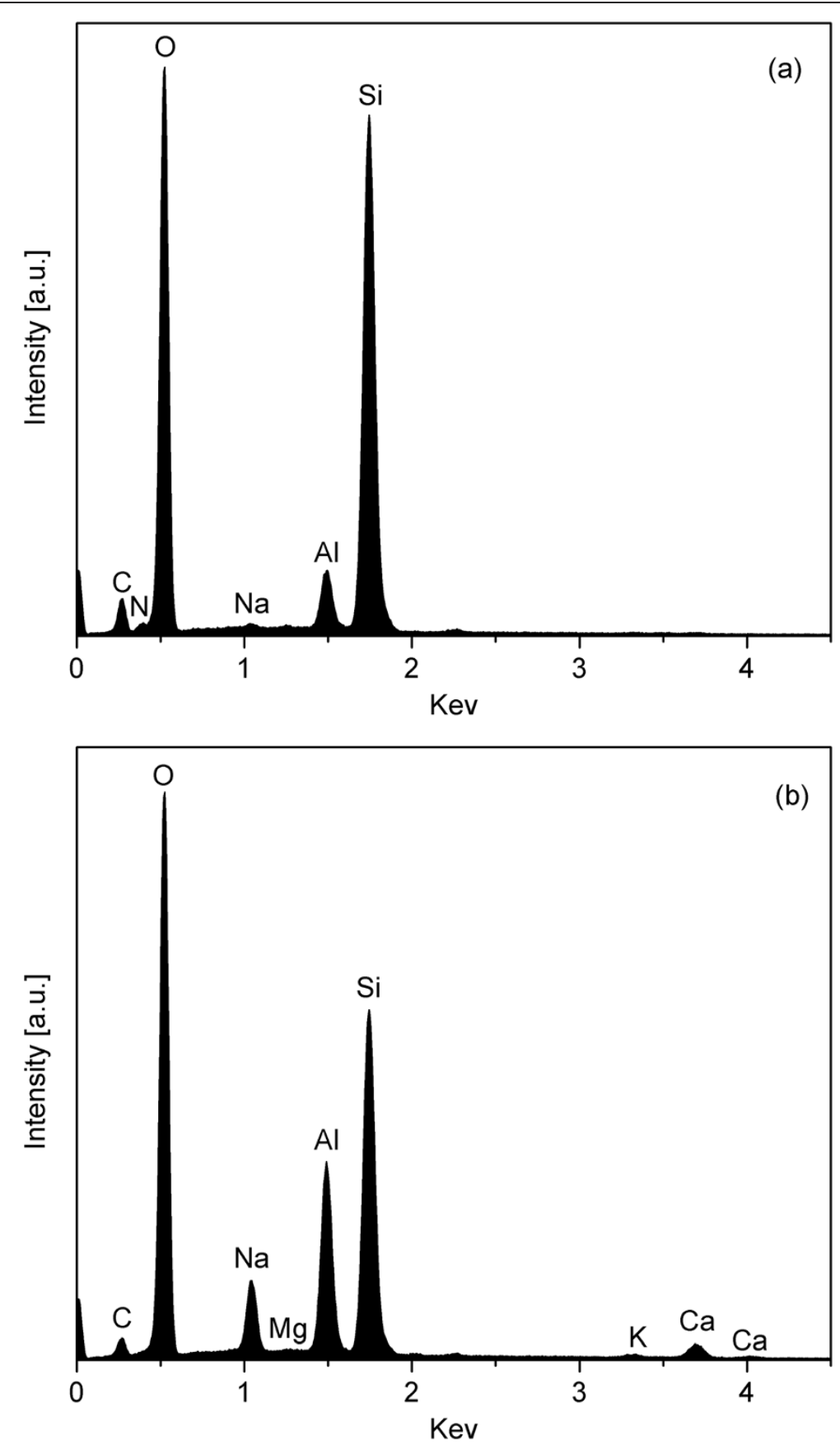

Figure 6 EDS spectra of the final product obtained from leached diatomaceous earth. (a) ZSM-5 crystal. (b) Mordenite crystal.

been used to prepare ZSM-5 zeolites with $\mathrm{SiO}_{2} / \mathrm{Al}_{2} \mathrm{O}_{3}$ molar ratios in the range $20-40$. Dealumination of the raw materials by acid leaching made it possible to reach appropriate $\mathrm{SiO}_{2} / \mathrm{Al}_{2} \mathrm{O}_{3}$ molar ratios and to reduce the amount of iron and other impurities in the raw materials. After mixing and aging for 24 hours, synthesis by hydrothermal treatment was carried out at $165^{\circ} \mathrm{C}$ either using leached metakaolin or leached diatomaceous earth as source of alumino-silica. The results clearly show for the first time that well-crystallized ZSM-5 can be directly prepared from both materials in combination with sodium hydroxide and $n$-butylamine under appropriate synthesis conditions. Reaction mixtures prepared from leached diatomaceous earth showed longer induction period due to the slower digestion of the fossilized diatom skeletons compared with microporous leached metakaolin. However, the use of leached diatomaceous earth allowed higher yield in ZSM-5 crystals within comparable synthesis times 
despite the formation of low contents of mordenite, which was related to the high calcium content of diatomaceous earth. Another considerable advantage of diatomaceous earth over kaolin is that diatomaceous earth does not require heat treatment at high temperature for metakaolinization.

\section{Competing interests}

The authors declare that they have no competing interests.

\section{Authors' contributions}

WAM carried out the experiments and drafted the manuscript under the supervision of JM and JH. GG assisted in the analysis of the experiments. All authors read and approved the final manuscript.

\section{Acknowledgements}

Swedish International Development Cooperation Agency (SIDA) is acknowledged for supporting the work financially. The Knut and Alice Wallenberg foundation is acknowledged for financially supporting the Magellan SEM instrument.

\section{Author details}

${ }^{1}$ Chemical Technology, Luleå University of Technology, Luleå, Sweden. ${ }^{2}$ Department of Chemistry, Faculty of Science and Technology, San Simon University, Cochabamba, Bolivia. ${ }^{3}$ Solid State and Theoretical Chemistry, Chemistry Research Institute, San Andres Mayor University, University Campus, Cota Cota, 27 Street, La Paz, Bolivia.

\section{Received: 10 April 2014 Accepted: 30 May 2014}

Published: 10 June 2014

\section{References}

Aliev AM, Mamedova UA, Samedov KR, Sarydzhanov AA, Agaeva RY (2011) Synthesis and physicochemical study of ZSM-5 high-silica zeolite from natural raw materials. Russ J Phys Chem A 85:288-292

Argauer RJ, Landolt GR (1972) Crystalline Zeolite Zsm-5 and Method of Preparing the same., 886A, 14 Nov 1972

Armaroli T, Simon LJ, Digne M, Montanari T, Bevilacqua M, Valtchev V, Patarin J, Busca G (2006) Effects of crystal size and Si/Al ratio on the surface properties of H-ZSM-5 zeolites. Appl Catal A Gen 306:78-84

Atta A, Ajayi O, Adefila S (2007) Synthesis of faujasite zeolites from Kankara kaolin clay. J Appl Sci Res 3:1017-1021

Bosch P, Ortiz L, Schifter I (1983) Synthesis of faujasite type zeolites from calcined kaolins. Ind Eng Chem Prod Res Dev 22:401-406

Caballero I, Colina FG, Costa J (2007) Synthesis of X-type zeolite from dealuminated kaolin by reaction with sulfuric acid at high temperature. Ind Eng Chem Prod Res 46:1029-1038

Chaisena A, Rangsriwatananon K (2005) Synthesis of sodium zeolites from natural and modified diatomite. Mater Lett 59:1474-1479

Chandrasekhar S, Raghavan P, Sebastian G, Damodaran AD (1997) Brightness improvement studies on 'kaolin based' zeolite 4A. Appl Clay Sci 12:221-231

Chareonpanich M, Namto T, Kongkachuichay P, Limtrakul J (2004) Synthesis of ZSM- 5 zeolite from lignite fly ash and rice husk ash. Fuel Process Technol 85:1623-1634

Chi ZQ, Li JH, Chen HF (2011) Synthesis of NaY zeolite molecular sieves from calcined diatomite. Adv Mater Res 236:362-368

Colina FG, Llorens J (2007) Study of the dissolution of dealuminated kaolin in sodium-potassium hydroxide during the gel formation step in zeolite $X$ synthesis. Microporous Mesoporous Mater 100:302-311

Colina FG, Esplugas S, Costa J (2001) High temperature reaction of kaolin with inorganic acids. Brit Ceram Trans 100:203-206

Colina FG, Esplugas S, Costa J (2002) High-temperature reaction of kaolin with sulfuric acid. Ind Eng Chem Res 41:4168-4173

Costa E, De Lucas A, Uguina MA, Ruiz JC (1988) Synthesis of 4A zeolite from calcined kaolins for use in detergents. Ind Eng Chem Res 27:1291-1296

De Lucas A, Uguina MA, Covian I, Rodriguez L (1992) Synthesis of 13X zeolite from calcined kaolins and sodium silicate for use in detergents. Ind Eng Chem Res 31:2134-2140
Feng H, Li C, Shan H (2009) In-situ synthesis and catalytic activity of ZSM-5 zeolite. Appl Clay Sci 42:439-445

Ford KIR (1992) Leaching of fine and pelletised Natal kaolin using sulphuric acid. Hydrometallurgy 29:109-130

Ghosh B, Agrawal DC, Bhatia S (1994) Synthesis of Zeolite A from Calcined Diatomaceous Clay: Optimization Studies. Ind Eng Chem Res 33:2107-2110

Jacobs PA (1981) Properties of the end members in the Pentasil-family of zeolites: characterization as adsorbents. Zeolites 1:161-168

Khatamian M, Irani M (2009) Preparation and characterization of nanosized ZSM-5 zeolite using kaolin and investigation of kaolin content, crystallization time and temperature changes on the size and crystallinity of products. J Iran Chem Soc 6:187-194

Kotasthane AN, Shiralkar VP (1986) Thermoanalytical studies of high silica ZSM-5 zeolites containing organic templateS. Thermochimica Acta 102:37-45

Kovo AS, Hernandez O, Holmes SM (2009) Synthesis and characterization of zeolite $\mathrm{Y}$ and ZSM-5 from Nigerian Ahoko Kaolin using a novel, lower temperature, metakaolinization technique. J Mater Chem 19:6207-6212

Madhusoodana CD, Kameshima Y, Yasumori A, Okada K (2001) Fast formation of ZSM-5 zeolite using microporous silica obtained from selective leaching of metakaolinite. Clay Sci 11:369-380

Madhusoodana C, Das R, Kameshima Y, Okada K (2005) Preparation of ZSM-5 zeolite honeycomb monoliths using microporous silica obtained from metakaolinite. J Porous Mat 12:273-280

Martins L, Peguin RPS, Urquiet-González EA (2006) Cu and Co exchanged ZSM-5 zeolites: activity towards no reduction and hydrocarbon oxidation. Quimica Nova 29:223-229

Mignoni ML, Detoni C, Pergher SBC (2007) Estudo da síntese da zeólita ZSM-5 a partir de argilas naturais. Quimica Nova 30:45-48

Murat M, Amokrane A, Bastide J, Montanaro L (1992) Synthesis of zeolites from thermally activated kaolinite. Some observations on nucleation and growth. Clay Min 27:119-130

Padovan M, Leofanti G, Solari M, Moretti E (1984) Studies on the ZSM-5 zeolite formation. Zeolites 4:295-299

Rangsriwatananon K, Chaisena A, Thongkasam C (2008) Thermal and acid treatment on natural raw diatomite influencing in synthesis of sodium zeolites. J Porous Mater 15:499-505

Reid (1982) Manufacture of zeolites. European Patent Office :68817, 24 June 1982

Robson H, Lillerud KP (2001) In Chapter 62 - MFI High-Alumina ZSM-5 Si(93), Al(7). Vol. pp. Elsevier Science, Amsterdam

Sang S, Chang F, Liu Z, He C, He Y, XU L (2004) Difference of ZSM-5 zeolites synthesized with various templates. Catal Today 93-95:729-734

Sanhueza V, Kelm U, Cid R (1999) Synthesis of molecular sieves from Chilean kaolinites: 1. Synthesis of NaA type zeolites. J Chem Technol Biotechnol 74:358-363

Sanhueza V, Kelm U, Cid R (2003) Synthesis of mordenite from diatomite: a case of zeolite synthesis from natural material. J Chem Technol Biotechnol 78:485-488

Sanhueza V, Kelm U, Cid R, López-Escobar L (2004) Synthesis of ZSM-5 from diatomite: a case of zeolite synthesis from a natural material. J Chem Technol Biotechnol 79:686-690

Sanhueza V, López-Escobar L, Kelm U, Cid R (2006) Synthesis of a mesoporous material from two natural sources. J Chem Technol Biotechnol $81: 614-617$

Shan W, Zhang Y, Wang Y, Xia J, Tang Y (2004) Synthesis of Meso-/Macroporous Zeolite (Fe, Al)-ZSM-5 Microspheres from Diatomite. Chem Lett 33:270-271

Shirazi L, Jamshidi E, Ghasemi MR (2008) The effect of Si/Al ratio of ZSM-5 zeolite on its morphology, acidity and crystal size. Cryst Res Technol 43:1300-1306

Tavolaro A, Drioli E (1999) Zeolite membranes. Adv Mater 11:975-996

Van Hooff JHC, Roelofsen JW (1991) Chapter 7 Techniques of Zeolite Characterization. In: van Bekkum EMF H, Jansen JC (eds) In Studies in Surface Science and Catalysis, Vol. 58. Elsevier, pp 241-283

Wajima T, Haga M, Kuzawa K, Ishimoto H, Tamada O, Ito K, Nishiyama T, Downs RT, Rakovan JF (2006) Zeolite synthesis from paper sludge ash at low temperature $\left(90^{\circ} \mathrm{C}\right)$ with addition of diatomite. J Hazard Mater 132:244-252

Wajima T, Shimizu T, Ikegami Y (2008) Zeolite synthesis from paper sludge ash with addition of diatomite. J Chem Technol Biotechnol 83:921-927

Weitkamp J (2000) Zeolites and catalysis. Solid State lonics 131:175-188 
Zhang Y, Gao W, Cui L (2007) In-situ Growth of ZSM-5 Zeolite on Acid-Activated Metakaolin. In: Ruren Xu ZGJC, Wenfu Y (eds) Studies in Surface Science and Catalysis, Volume 17. Elsevier, pp 426-431

Zhao H (2005) The difference between ZSM-5 zeolites manufactured from various synthesis systems and their catalytic performances. J China Petroleum Petrochem Technology 3:49-55

doi:10.1186/2193-1801-3-292

Cite this article as: Aguilar-Mamani et al:: Comparison between leached metakaolin and leached diatomaceous earth as raw materials for the synthesis of ZSM-5. SpringerPlus 2014 3:292.

Submit your manuscript to a SpringerOpen ${ }^{\circ}$ journal and benefit from:

- Convenient online submission

- Rigorous peer review

- Immediate publication on acceptance

- Open access: articles freely available online

- High visibility within the field

- Retaining the copyright to your article

Submit your next manuscript at $>$ springeropen.com 